\title{
CAMÕES, O POETA DO IMAGINÁRIO ULTRAMARINO
}

\author{
CAMÕES, THE POET OF THE \\ OVERSEAS IMAGINARY
}

Daniel Vecchio ${ }^{1}$

\section{RESUMO}

Neste artigo, procuraremos apontar, com Os Lusíadas (1572), como a épica camoniana representa as subjetividades provenientes do ambiente das descobertas ultramarinas, integrando-as num todo significativamente problemático. É nessa perspectiva que nos ateremos a sua famosa obra, no intuito de apreender uma das lições que o poeta pretendeu registrar: o desejo tão comum, em sua época, de ir às Índias para enriquecer ou mesmo para indagar e ver tudo, desejo esse de descoberta que, segundo o próprio Camões, não vem sem peleja, dor e angústia. Para tal interpretação, partimos da leitura de Felizi ao examinar como o poeta empregou a palavra descobrimento ou descoberta não apenas no seu sentido histórico, mas também num sentido mais filosófico, situando-a entre a verdade e o engano.

PALAVRAS-CHAVE: Viagem; imaginário; Portugal.

\section{ABSTRACT}

In this article, we will point out, with Os Lusíadas (1572), how the camonian epic represents the subjectivities coming from the overseas discoveries context, integrating them into a significantly problematic whole. It is from this perspective that we will focus on his famous work, in order to apprehend one of the lessons that the poet intended to record: the desire so common in his time to go to the Indies to enrich or even to inquire and see everything, a discovery that, according to Camões, does not come without struggle, pain and anguish. For this interpretation, we begin with the reading of Felizi studies, specifically when is exanimate how the poet uses the word discovery not only in its historical sense, but also in a more philosophical sense between truth and deception.

KEYWORDS: Travel; imaginary; Portugal. 
Neste artigo, procuraremos apontar, com Os Lusíadas (1572), como a épica camoniana representa as subjetividades provenientes do ambiente das descobertas ultramarinas, integrando-as num todo significativamente problemático. É nessa perspectiva que nos ateremos a sua famosa obra, no intuito de apreender uma das lições que o poeta pretendeu registrar: o desejo tão comum, em sua época, de ir às Índias para enriquecer ou mesmo para indagar e ver tudo, desejo esse de descoberta que, segundo Camões, não vem sem peleja, dor e angústia, como expressado no seguinte verso: "Ó descoberto engano inopinado, / [...]" (Camões, 2000, II, 30).

Para tal interpretação, partimos da leitura de Felizi ao examinar como o poeta lusitano empregou a palavra descobrimento ou descoberta não apenas no "sentido histórico dos descobrimentos", mas também associada ao "descobrimento de alguma cilada ou engano" (Felizi, 2016, p. 168). Esse sentido é explícito no seguinte trecho da obra de Camões: "O recado que trazem é de amigos, / Mas debaixo o veneno vem coberto, / Que os pensamentos eram de inimigos, / Segundo foi o engano descoberto" (Camões, 2000, I, 105).

Essa e outras antíteses que representam a tensão entre encobrimento e descobrimento afloram na épica camoniana, fazendo das antíteses escondido/amostrado, verdade/engano e luminoso/oculto, relações de força que apontam para uma duplicidade do olhar viajante, ávido por descobrir lugares e criaturas, mesmo num contexto em que as viagens oceânicas já tinham se tornado uma prática mais comum entre os portugueses: "Cum delgado cendal as partes cobre / De quem vergonha é natural reparo; / Porém nem tudo esconde nem descobre / O véu, dos roxos lírios pouco avaro; / Mas, pera que o desejo acenda e dobre, / Lhe põe diante aquele objeto raro. / Já se sentem no Céu, por toda a parte, / Ciúmes em Vulcano, amor em Marte" (Camões, 2000, II, 37).

A apreensão antitética desse "natural reparo" das descobertas implica na relação semântica com a imagem dos bastidores que eram comuns a quem havia se aventurado por mares e terras pouco conhecidos no tempo de Camões. A exemplo desse jogo de antíteses, devemos recordar, antes de tudo, do significado paradoxal da palavra grega aletheia, em que é preciso notar sua natureza dupla: esquecimento e não-esquecimento (Heidegger, 2008). Literalmente traduzida por desocultamento, essa palavra grega é formada pelo prefixo negativo $a$, enquanto lethes se associa ao mítico rio infernal do esquecimento. "Não esquecer" é o que a língua grega revela como essencial para perceber que a verdade não é apenas a negação da falsidade, mas também um processo de ocultamento sobre a própria percepção de descobrimento de lugares e de memórias.

Nesse sentido, não afirmaria, por exemplo, Vitorino Magalhães Godinho (1991, p. 116) que "A glória é uma das formas do esquecimento"? Assim também não seria a épica para Camões? Em todo caso, nesse ato enigmático de tentar perceber o real apreendido pelo viajante ultramarino, Os Lusíadas de Camões toma como foco o resgate memorial da narrativa da primeira viagem de Vasco da Gama ao Oriente, incluindo suas expe- 
riências tanto sensitivas quanto imaginárias. Representando o desvelamento das rotas orientais, a viagem do Gama de Camões parece ter estimulado a personagem do navegador a não se deixar tomar por completo pelos domínios imaginários, sobretudo religiosos, suscitados ao longo de sua extensa e incerta empresa marítima.

Assim o representou Camões, explorando para isso diversos aspectos da realidade empírica dos viajantes da época, sendo tais aspectos provenientes da astronomia, das ciências da natureza e da etnografia, informações que foram colhidas com o mais vivo interesse naturalista do poeta, no decorrer de sua estadia oriental. ${ }^{2}$ Ao lado de um vasto grupo de europeus que queria juntar o seu nome aos dos heróis pátrios e conhecer os novos e fabulosos mundos até então divulgados pela carta do Preste João e pelos relatos de Marco Polo, Camões percorrera por muitos territórios distantes. Ao situar-se na Arábia deserta, por exemplo, cujo ambiente magistralmente evoca em seus versos, o poeta lamenta-se por sentir-se enquanto viajante errante, com sua alma sendo parte de um mundo muito mais longínquo e diverso do que esperava ou podia prever, vida repartida em pedaços a cada passo, a cada língua ouvida, a cada costume observado, enfim, a cada território visitado e vivido:

Assi fomos abrindo aqueles mares, / Que geração algũa não abriu / As novas ilhas vendo e os novos ares / Que o generoso Henrique descobriu; / De Mauritânia os montes e lugares, / Terra que Anteu num tempo possuiu, / Deixando à mão esquerda, que à direita / Não há certeza doutra, mas suspeita (Camões, 2000, V, 4).

Nesses versos é possível perceber o quanto a constituição do ambiente físico é importante para a descrição do espaço observado pelo olhar viajante de Camões, espaço esse que não existe por si só, sendo representado também pelas memórias passadas de outras terras visitadas, senão imaginadas. Ademais, por vezes, o cenário memorialístico é substituído por lamentações expressivas do próprio epos do poema, dando-nos a entender a presença de uma voz experiente, de quem já viu o Oriente e experimentou as conseqüências do engano: "Despois de aparelhados, desta sorte, / De quanto tal viagem pede e manda, / Aparelhámos a alma pera a morte, / Que sempre aos nautas ante os olhos anda" (Camões, 2000, IV, 86).

Seria esse lamento do poeta o retrato da sua própria angustia por viver uma vida que "ante os olhos anda", vida passageira diante de um mundo tão vasto por descobrir e compreender? Segundo Pedro Mariz, tal ânsia de Camões o fez ser enviado às partes da China, tendo estado inclusivamente em Macau, onde teria sido vítima de um naufrágio, provavelmente na foz do rio Mecom, no Camboja, fato a que alude na sua própria épica, evocando a célebre salvação, a nado, do manuscrito de sua obra: "Este [Mecom] receberá plácido e brando, / No seu regaço os Cantos que molhados / Vêm do naufrágio triste e miserando, / Dos procelosos baxos escapados, / Das fomes, dos perigos grandes, quando / Será o injusto mando executado / Naquele cuja Lira sonorosa / Será mais afamada que ditosa" (Camões, 2000, X, 128). 
Em nossa leitura, Os Lusíadas suscita a tensão do encobrimento imaginário sobre o descobrimento físico de mundos desconhecidos, espécie de olhar interiorizado de um Oriente que, apesar de ser exteriorizado pelo sentido da visão, não deixa de revelar a percepção pessoal do poeta que, além de sensitiva, é, sobretudo, mítica. Desse modo, numa linha que tenta se aproximar e ao mesmo tempo se afastar da tão desejada veracidade dos relatos de viagem, Camões atenta-se às ambiguidades do realismo das paisagens e dos objetos observados. Desde o estudo do Conde de Ficalho, A Flora dos Lusíadas (1880), muitos adentraram na épica camoniana no sentido de abordar apenas o seu tom empírico, que de fato se sobressai em várias estrofes, proporcionando-nos um conhecimento apreendido em primeira mão sobre gentes, floras e faunas orientais, todavia, fato é que, ao longo das últimas cinco ou seis décadas, muito comentadores têm emitido sobre tal obra épica um olhar preponderante de viajante curioso.

Em função desses aspectos, atentemo-nos primeiro aos versos em que Camões valoriza sua experiência direta para asseverar a veracidade física do que observou e sentiu numa de suas passagens pelo Oriente: "Os casos vi que os rudos marinheiros, / Que têm por mestra a longa experiência, / Contam por certos sempre e verdadeiros, / Julgando as cousas só pola aparência, / E que os que têm juízos mais inteiros, / Que só por puro engenho e por ciência / Vem do mundo os segredos escondidos, / Julgam por falsos ou mal entendidos" (Camões, 2000, V, 17). A marca da experiência e do engenho se propõe claramente, aqui, enquanto percepção decorrente do engano, visão além da aparência, ciência do descobrimento demonstrada pelo verbo "ver", que é frequentemente usado no poema para designar não somente a experiência do mar e da terra vista, mas da experiência vivida. Portanto, esse contato visual do viajante vai muito além de uma realidade material ou fenômeno natural. Percebamos, ainda, as mesmas características nos versos seguintes, prestando atenção aos empregos desse mesmo verbo: "Vi, claramente visto, o lume vivo / Que a marítima gente tem por santo, / Em tempo de tormenta e vento esquivo, / De tempestade escura e triste pranto. / Não menos foi a todos excessivo / Milagre, e cousa, certo, de alto espanto, / Ver as nuvens, do mar com largo cano, / Sorver as altas águas do Oceano" (Camões, 2000, V, 18).

Em outras palavras, não menos espantoso era assistir aos espetáculos da natureza, fenômenos ainda inexplicáveis aos olhos do viajante da época. Além disso, nas páginas de Os Lusíadas, o poeta fala a D. Sebastião a propósito da disciplina exigida dos marinheiros portugueses, que não se aprende somente "na fantasia, / Sonhando, imaginando ou estudando, / Senão vendo, tratando e pelejando" (Camões, 2000, X, 153). Pouco se atentando a essas e outras marcas, Os Lusíadas foi considerado pela crítica geral um poema renascentista elaborado com primazia por elementos empíricos, representando, assim, o referido "espírito novo", poema de afirmação da importância do ver terras e gentes antes só registradas (imaginadas) por lendas (Almeida, 2013). 
Camões é de fato um entusiasta das realidades que vai descobrindo nos novos mundos e, como vemos nas estâncias d' Os Lusíadas, mostra aceitar indiscutivelmente a ideia de que o conhecimento começa com a experiência: trata-se do primeiro passo para a verdade que se movimenta da visão à intelecção. Mas, nem por isso podemos dizer que há n'Os Lusíadas uma negação do maravilhoso enquanto operador da realidade apreendida, como muitos anacronicamente afirmam (Rosa, 1998), enxergando apenas a concretização científica que deu base aos empreendimentos marítimos dos portugueses, acontecimento histórico ímpar para o destino geopolítico de toda humanidade. ${ }^{3}$ Porém, embora Camões defenda e valorize o papel da experiência sensitiva nos descobrimentos, sua obra parte dessa percepção para melhor abranger os problemas associados ao horizonte de expectativas dos marinheiros lusitanos que se encontravam no Oriente.

A leitura atenta desse poema revela, portanto, que, além de se alicerçar em categorias representativas exteriores ao sujeito, como o tempo e o espaço, eixos fundamentais para a escrita de Os Lusíadas, a verdade é que a perspectiva lírica do poeta nunca deixa de imprimir suas marcas simbólicas e imaginárias na epopeia, "o que faz que os objetos considerados deixem de pertencer a um campo somente espaço-temporal distinto do sujeito que os interpreta" (Fraga, 2010, p. 47). Ademais, ao abordarmos o significado do mito n'Os Lusíadas, é preciso pôr de lado as concepções tradicionais segundo as quais ele teria no poema uma função apenas ornamental, ou então restritamente alegórica. Por outro lado, segundo Saraiva, “o plano mitológico é n’ Os Lusíadas o que há de essencial, nele residindo a vida e o significado profundo do poema” (Saraiva, 1982, p. 123).

Em favor desse posicionamento, Jorge de Sena inaugura, ainda na década de 1940, uma nova vertente crítica de Camões e d’Os Lusíadas. Em seus estudos pioneiros, Sena faz o seguinte apontamento: "De Os Lusíadas tem-se estudado tudo: a fauna, a flora, a astronomia, a geologia, e, vastamente, as fontes. [...], a questão que nos ocupa é muito diversa" (Sena, s./d., p. 57). Tratou-se de um salto qualitativo na análise d'Os Lusíadas ao se propor como tarefa basilar, aos seus estudiosos, ler a obra épica como uma estrutura muito mais ampla e mais complexa do que uma mera representação sensorial das viagens ultramarinas:

Mas a tradição crítica, despercebendo-lhe inteiramente a enunciação, percebeu-lhe apenas parcialmente o enunciado. E uma leitura atenta destes dois planos nos revela que $\mathrm{Os} \mathrm{Lu}$ síadas atravessou os séculos como uma obra desconhecida. Estudando-se a obra a fundo, usando-se para isto as necessárias ferramentas teóricas, percebe-se que, longe de estarmos ante uma obra petrificada, cujo sentido já foi há séculos estabelecido, estamos ante um poema gigantesco, ainda repleto de revelações que nos oferecem descobertas surpreendentes (Nóbrega, 2012, p. 58). 
Chegamos, neste ponto, à questão de que a descoberta, na épica camoniana, transcende o texto, implicando problemas interpretativos a sua recepção ao longo de séculos. Depois do apelo de Sena, estudar Os Lusíadas passou a exigir uma observação mais atenta ao seu enunciado e a sua enunciação, sem deixar-se limitar pelas rupturas empíricas e científicas trazidas à tessitura do poema. Assim se nos revela, sob a camada épica epidérmica da narrativa do epos de Camões, uma profundidade subjacente, cujas irrupções intermitentes no fio discursivo provocam as já referidas dissonâncias entre o encoberto e o descoberto, os imaginários e as sensações que refletem na dupla viagem ao Oriente que é circunscrita na obra: a viagem do Gama e a de Camões. Essa coexistência revela-nos uma conjunção de fatores semânticos, indicativos dos enganos e das experiências vividas pela comunidade lusitana em terras longínquas.

Em vista disso, Camões nos oferece um surpreendente diagnóstico dos imaginários marinheiros que ainda pairavam sobre a mentalidade dos portugueses do Oriente. O poeta nos mostra que por baixo da experiência como "madre das coisas", há sempre uma dor que assola a verdade aparente, falsas sensações e impressões do vi-ver, ou melhor, de um "vi" sem "ver". Camões aprendeu essa lição, que se articula no pensamento renascentista com a concepção cristã do homo viator, do homem que caminha pelo mundo tendo por meta uma peregrinação, ou seja, um rito itinerante que proporcionará sua purificação, a salvação da sua alma perante os enganos acumulados em vida. Dentre as qualidades apreendidas pelo purgativo olhar do viajante, há, segundo Camões, uma quantidade de enganos que se agregam aos sentidos, fazendo da realidade oriental um verdadeiro cenário teatral que prega peça a todos os lusitanos que lá chegam ávidos por relatar sua fama e riqueza:

Contar-te longamente as perigosas / Cousas do mar, que os homens não entendem, / Súbitas trovoadas temerosas, / Relâmpados que o ar em fogo acendem, / Negros chuveiros, noites tenebrosas, / Bramidos de trovões, que o mundo fendem, / Não menos é trabalho, que grande erro, / Ainda que tivesse a voz de ferro (Camões, 2000, V, 16).

Mesmo feitas de ferro, as palavras enferrujam os sentidos. O som do trovão, os estalos do mastro e o ecoar das vozes dos marinheiros se misturam nessa senda de fragilidades humanas que compõe o entorno marítimo. No poema, os imaginários são paradoxalmente encobertos pelos sentidos, "segredos escondidos" que emergem nessa traiçoeira empresa: "Eis vem o pai, com ânimo estupendo, / Trazendo fúria e mágoa por antolhos, / [...]" (Camões, 2000, X, 33).

Dentre os elementos que antecedem a visão do viajante, ou seja, que se ajustam a esse "antolhar" camoniano, estão representadas, no trecho supracitado, as tempestades da alma alinhadas ao próprio ritmo fulgurante dos ventos. Com esses e outros detalhes perceptivos, aos poucos percebemos que, para Camões, a longa viagem oceânica entre Portugal e o Oriente 
não era, ainda em seu tempo, uma rotineira e mecânica atividade. $\mathrm{O}$ alto mar ainda encontrava-se conotado com o perigo e a instabilidade mental do próprio navegante, numa tradição que o humanismo do Velho do Restelo incorpora muito bem: "Já que nesta gostosa vaidade / Tanto enlevas a leve fantasia, / Já que à bruta crueza e feridade / Puseste nome, esforço e valentia, / [...]” (Camões, 2000, IV, 99).

No entanto, em contraposição ao Velho do Restelo, surge o áureo capitão Vasco da Gama, personagem que aparentemente parece ser central na épica camoniana, tendo em vista a maturidade em que se apresenta esse navegador, especificamente na cena em que responde positivamente ao rei D. Manuel, o Venturoso, depois de ter sido escolhido para comandar a famosa armada de 1497:

[Dom Manuel] "Eu vos tenho entre todos escolhido / Pera ũa empresa, qual a vós se deve, / Trabalho ilustre, duro e esclarecido, / [...]. // [Vasco da Gama] Ó Rei subido, / Aventurar-me a ferro, a fogo, a neve / É tão pouco por vós, que mais me pena / Ser esta vida cousa tão pequena. // Imaginai tamanhas aventuras / Quais Euristeu a Alcides inventava: / O lião Cleonéu, Harpias duras, / O porco de Erimanto, a Hidra brava, / Decer enfim às sombras vãs e escuras / Onde os campos de Dite a Estige lava; / Porque a maior perigo, a mor afronta, / Por vós, ó Rei, o esprito e carne é pronta (Camões, 2000, IV, 79-80).

O que temos no excerto acima é a representação de um Vasco da Gama prudente e convicto da realidade oriental em que vai adentrar, realidade essa que aparece isenta de lugares divinos e criaturas espantosas, com exceção obviamente da figura do Adamastor. Trata-se, acima de tudo, de um personagem não menos exigido pela lição empírica na qual a poética de Os Lusíadas é também marcada. Contudo,

No entrecruzamento dos ideais heróicos da epopeia e do desânimo maneirista, no choque entre o ter ultrapassado o que a força humana prometia, a "vil tristeza" do presente e a fragilidade individual, encontra-se, noutra escala, com outra dimensão e expressão, o mesmo choque que se encontra na Lírica entre o mundo ideal cantado por Camões e o universo imperfeito e injusto que o exclui da harmonia, perseguindo-o malevolamente e obrigando-o a ser, em toda a extensão dos termos, "peregrino vago e errante". (Fraga, 2010, p. 57).

Sendo assim, em paralelo a essa figura apolínea do Gama d'Os Lusíadas, o epos de Camões nos sugere imagens mais complexas da percepção viajante, extrapolando o realismo pleno e estável, a começar pelas angústias e nostalgias provocadas por seu próprio desterro: “[...]: - Ó gente, que a Natura / Vizinha fez de meu paterno ninho, / Que destino tão grande ou que ventura / Vos trouxe a cometerdes tal caminho?" (Camões, 2000, VII, 30). Sua tristeza parece converter-se, por vezes, em impulso para redobrar as fragilidades dos marinheiros, em sua maioria degredados e dester- 
rados, dando suprema atenção aos enganos provocados pelas expectativas daqueles que compartilhavam dessa condição, engano gerador dos males e infortúnios suportados pelo poeta ao longo de sua estadia no Oriente.

Tais enigmáticos enganos, que afrontam a experiência do epos camoniano, evidencia a impotência humana, sendo esse embate consequência direta do aperfeiçoamento de meios técnicos de navegação e registro que, mesmo alicerçados em dados empíricos, acabam confrontados pelos mistérios de uma natureza terrivelmente desconhecida e fascinante, que desafia a percepção desse "bicho da terra tão pequeno" de que fala o poeta (Camões, 2000, I, 106). Em outras palavras, essa crítica

[...] se estende a um Portugal incapaz de ler, do qual o Gama é apenas triste metonímia. Camões, metonímia da decepção, pois pretensa metonímia dos "barões assinalados" (Lus, I, 1, 1), é vítima de um processo muito real, pois histórico, e sua tarefa de ler a história será, portanto, ingloriosa e terá, necessariamente, que se revestir de um caráter revolucionário. Eduardo Lourenço tem toda a razão quando fala de realidade: Os Lusíadas, épico fincado numa viagem real que não é absorvida sem problemas pelo canto, dignifica-a pelo amor e pelo mito mas é recebido por "gente surda e endurecida" (Lus, X, 145, 4), incapaz de ouvir o que quer que seja já que "quem não sabe arte, não na estima". A revolução proposta pelo poema, "espelho insuperável e não ainda superado", é sempre adiada (Maffei, 2014, p. 134).

Camões, ao aperceber-se da frágil e complexa condição do ser frente a um mundo tão grande e diverso, lamenta a vida poeticamente. Como já assinalou Garcez, nessa senda de limites e incapacidades, o poema camoniano teve a sutileza de registrar a querela entre o saber empírico e o livresco, conflito esse que marca, sobretudo, o período renascentista: "Vejam agora os sábios na escritura / Que segredos são estes da Natura!" (Camões, 2000, V, 22).

Lembremos que, tendo em vista o conhecimento sensorial que cerca a explicação racional para os fenômenos claramente vistos, somos lançados pelo epos do poema para diante do mencionado gigante Adamastor, obstáculo mítico-geográfico que, mesmo ainda em seu século, dividia o mundo conhecido do desconhecido: "Fui dos filhos aspérrimos da Terra, / Qual Encélado, Egeu e o Centimano; / Chamei-me Adamastor, e fui na guerra / Contra o que vibra os raios de Vulcano; / [...].” (Camões, 2000, V, 51).

Em Os Lusíadas, a figura do gigante Adamastor faz eco aos temores sentidos pelos marinheiros portugueses nas proximidades do rochoso cabo da Boa Esperança, cognominado anteriormente de cabo das Tormentas. A imagem mitológica construída pelo poeta não teria surgido sem numerosos relatos orais e escritos relativos à temível passagem: "Enquanto os navios avançam na sua direção, eis que o cabo, como a imagem impressiva de todos os outros cabos, apresenta-se aos capitães e às tripulações marítimas como uma estátua disforme e gigantesca, réplica do colosso de Rhodes." (Delumeau, 1989, p. 52). 
Ao mesmo tempo em que houve um alargamento da razão, indiscutivelmente retratado na épica de Camões, "houve também um alargamento muito profundo da melancolia, da visão sombria, pessimista e desesperançada da realidade" (Garcez, 2008, p. 227), e Camões é o autor por excelência desses aspectos em língua portuguesa. Se a razão foi desafiada para compreender e explicar fenômenos antes desconhecidos, vemos que persistia a subjetividade do homem europeu, ainda em busca de explicações sobre criaturas e paragens místicas:

A exploração pelos portugueses da costa ocidental africana e, depois, dos distantes mares e terras do Oriente poderia assimilar-se, de certo modo, a uma vasta empresa exorcística. Dos demônios e fantasmas que, através de milênios, tinham povoado aqueles mundos remotos, sua passagem vai deixar, se tanto, alguma vaga ou fugaz lembrança, em que as invenções mais delirantes só aparecem depois de filtradas pelas malhas de um comedido bom-senso (Holanda, 2010, p. 48).

Trata-se de um apanhado das visões sombrias que assolavam a marinharia, das forças que regiam o mundo de Camões e que promoviam intensa desconfiança nas explicações científicas de então, optando o poeta por uma sensibilidade alternativa aos enganos mundanos provocados por seu campo sensorial. N'Os Lusíadas, nos chama a atenção, portanto, a tensão operada pelo mundo sobrenatural que se desenvolve agregadamente ao enredo do mundo físico e oficialmente histórico. Cabe notar aqui, por isso, toda a problemática trazida pela filosofia platônica no contexto intelectual de Camões que, significativamente, tensiona os dois planos de conhecimento: a razão e a sensação, planos que, há séculos, acompanha a problemática do testemunho e do relato de viagem enquanto registros do real.

Tais elementos não deixam de estar presentes na estruturação épica de Camões, cuja noção de experiência, defendemos aqui, vai muito além da experiência cientificamente construída ou colhida da observação e dos livros, visando também o contato direto não com os objetos, mas com as próprias imagens mentais dos objetos e dos espaços, fazendo enxergar a ele e aos outros a própria loucura ou seus próprios desenganados desejos: "E ponde na cobiça um freio duro, / E na ambição também, que indignamente / Tomais mil vezes, e no torpe e escuro / Vício da tirania infame e urgente; / Porque essas honras vãs, esse ouro puro, / Verdadeiro valor não dão à gente: Milhor é merecê-los sem os ter, / Que possuí-los sem os merecer" (Camões, 2000, IX, 93).

Em defesa de uma noção de experiência mais ampla e não dependente somente de suas materialidades ou apenas de suas subjetividades, mas composta por ambos, Os Lusíadas proporciona ao leitor a experiência do (ant)olhar como ferramenta plural de percepção da realidade. Entre olhares encobridores e descobridores, o epos do poema traça diferenças entre o "olhar cobiçoso", o "olhar interessado" e o "olhar interesseiro", sendo o mais exigente aquele que o próprio poeta diz se recorrer: um olhar mais aprofundado, engenhoso e científico, uma ciência para além dos olhos. 
Logo, opõe-se, na expressão camoniana, a "visão" exigente dos "que têm juízos mais inteiros" à dos "rudos marinheiros" que sabem "julgar só pela aparência” (visão ou sensação), mas que podem distinguir os "casos" por "certos sempre e verdadeiros" (Camões, 2000, V, 17). É levando em consideração tais olhares que Camões representa poeticamente sua percepção de Oriente, enquanto ele próprio, errático viajante expulso de sua terra natal, passa a construir, depois de velho, um olhar diferente daquele que detinha quando partiu do Restelo, e que se propõe mais aguçado e preparado para deparar-se com novas paisagens e novas gentes, sabendo da tendência daqueles que se limitam em avistar e buscar imagens orientais por meio de suas expectativas cobiçosas e paradisíacas.

Retomemos aqui os versos dirigidos ao rei D. Sebastião, por exemplo, em que o poeta clarifica melhor o seu pensamento quanto a esse ponto, relevando o ver, o comerciar e o pelejar, sem desprezar, por isso, o estudo e o engenho: "Nem me falta na vida honesto estudo, / Com longa experiência misturado, / Nem engenho, que aqui vereis presente, / Cousas que juntas se acham raramente" (Camões, 2000, X, 154).

Desse modo, Camões, no propósito de identificar a vocação histórica do povo lusitano com os feitos das viagens intercontinentais, especialmente a partir da viagem de Vasco da Gama, sublinha, em cada verso de sua épica, o que de mais universal se consubstancia no agir de seus heróis imperfeitos, submetidos às novidades empíricas e aos imaginários do século, motivados por sonhos, profecias e, sobretudo, pelo medo da morte em mares tempestuosos.

N'Os Lusíadas, o menor sintoma da natureza externa corresponde a grandes sintomas da natureza interna pelos quais ela é apreendida. Uma terra fértil, uma cultura desconhecida, um fenômeno natural nunca visto antes: tomando conhecimento dos símbolos da tradição, todas essas novidades eram absorvidas intensamente pelo mundo previsto pelos navegantes. Percebe-se que essa reflexão pode ser inferida no canto $\mathrm{X}$ de $\mathrm{Os}$ Lusíadas, em que o navegador Vasco de Gama e sua esquadra aportam na Ilha dos Amores. Nessa ilha, Gama é recebido pela ninfa Tétis, a mais próxima de Vênus, que o leva ao pico mais alto desta ilha, onde lhe mostra a Máquina do Mundo, cujo funcionamento ptolomaico de todo o universo não passaria de um sistema limitado e imaginado pelo homem: "Vês aqui a grande máquina do Mundo, / Etérea e elemental, que fabricada / Assi foi do Saber, alto e profundo, / Que é sem princípio e meta limitada." (Camões, 2000, X, 80).

Dúbia é essa imagem do mundo apresentada por Tétis, com seus círculos concêntricos e totalizadores, formados por um derredor invisível e misterioso, de "meta limitada". Eis o drama da encoberta "máquina do mundo" que Camões nos apresenta, o que indica o limite imprimido pela percepção humana sobre o seu funcionamento, produto da ciência e do imaginário de quem a criou: 
Aqui, a navegação e os descobrimentos têm um caráter inestimável como ampliação dos limites do cosmo e, portanto, dos limites do homem que por ele viaja. Não se trata mais de ultrapassar tentações, mas de ultrapassar limites. A tentação é, ao contrário, ficar aquém desses limites, como o Adamastor, que, em sua paixão por Tétis, não chega a atingir o amor elevado da Vênus Celestial e, com isso, faz o caminho inverso ao da divinização do herói, caindo ao nível do infra-humano (Barcellos, 1997, p. 19).

Nesse episódio da ilha do amor, a máquina do mundo representa a imagem do universo configurada pelos próprios viajantes lusos (ou mesmo por sua tradição cultural). Prova disso é que a revelação oferecida pela Deusa não é a do funcionamento do universo em si, mas dos limites desse mundo imaginado, ou seja, de seus mares, continentes e ilhas ainda não descobertos. Tal é matéria-prima descrita pelo poeta que evidencia, de proa à popa, a experiente, porém ainda ansiosa e frágil percepção dos viajantes com quem convivera por longo tempo.

Com isso, o astuto poeta se mostra também como um navegador experiente que descobriu parte dos imaginários que encobertavam a visão portuguesa do Oriente, inevitável entrave para o aprimoramento dos contatos ultramarinos. Portanto, diante da representação de sua anábase pessoal, Camões nos ajuda a compreender o olhar desses soldados erráticos das últimas décadas do século XVI, no qual se cruzam pensamentos, desejos e sentidos acumulados durante dois séculos de navegação, e cujo desequilíbrio contribuiu para colocar em xeque o poderio imperial lusitano que, posteriormente, fora subjugado à coroa de Castela.

\section{REFERÊNCIAS BIBLIOGRÁFICAS}

ALMEIDA, Onésimo Teotónio. Camões e o espírito empírico da modernidade. Academia da Marinha - Memórias. Lisboa, v. XLIII, p. 309-320, 2013.

BARCELLOS, J. C. Descobrimentos portugueses: teologia e literatura. In: CORRÊA, Alamir Aquino (org.). Navegantes dos Mares às Letras: ideário da navegação na literatura portuguesa. Londrina: Ed. UEL, p. 3-10, 1997.

CAMÕES, Luís de. Os Lusíadas. $4^{a}$ ed. Lisboa: Instituto Camões, 2000.

DELUMEAU, Jean. História do Medo no Ocidente: uma cidade sitiada (1300-1800). Trad. Maria Lúcia Machado. São Paulo: Companhia das Letras, 1989.

FELIZI, Natasha. Os Lusíadas, Poema do Descobrimento. Abril, Niterói, v. 8, nº 16, p. 167-176, 2016.

FRAGA, Maria do Céu. O tempo e o espaço: a errância na lírica camoniana. Floema, no 7, p. 43-59, 2010.

GARCEZ, Maria Helena Nery. O alargamento da razão na literatura de viagens do século XVI. Via Atlântica, São Paulo, n 13, p. 219-228, 2008. 
GODINHO, Vitorino Magalhães. Os descobrimentos e a economia mundial. Lisboa: Editorial Presença, 1991, v.1.

HEIDEGGER, Martin. Parmênides. Trad. Sérgio Mário Wrublevski. Petrópolis: Vozes; Bragança Paulista: Editora Universitária São Francisco, 2008.

HOLANDA, Sérgio Buarque de. Visão do Paraíso. Os motivos edénicos no descobrimento e colonização do Brasil. São Paulo: Companhia das Letras, 2010.

MACHADO, Álvaro Manuel. O mito do Oriente na Literatura Portuguesa. Lisboa: Biblioteca Breve, 1983.

MAFFEI, Luis. Ler Camões com Eduardo Lourenço ou Camões no futuro com Paulo da Gama e outras amorosas companhias. Revista Letras. Curitiba, no 90, p. 131-148, 2014.

NÓBREGA, Luiza. Um poema, duas viagens: dicção e contradicção n’Os Lusíadas. Convergência Lusíada, no 27, p. 57-63, 2012.

ROSA, Silvina. Os Lusíadas e a história. In: IANNONE, C. A.; GOBBI, M. V. Z.; JUNQUEIRA, R. S. (orgs.). Sobre as naus da iniciação: estudos portugueses de literatura e história. São Paulo: Unesp, p. 255-270, 1998.

SARAIVA, António José. Para a História da Cultura em Portugal. Amadora: Bertrand, 1982.

SENA, Jorge de. A estrutura de Os Lusíadas e outros estudos camonianos e da poesia peninsular o século XVI. Lisboa: Portugália, s./d.

Recebido para publicação em 01/06/19

Aprovado em 07/08/19

\section{NOTAS}

1 Mestre em Estudos Literários e licenciado em História pela Universidade Federal de Viçosa (UFV). Atualmente é pesquisador-doutorando do CNPq pelo Programa de Pós-Graduação em História Cultural da Universidade Estadual de Campinas (UNICAMP), com formação complementar pelo PPG em Literatura Portuguesa da Universidade de São Paulo (USP).

2 "Desde Aquilino Ribeiro e António José Saraiva, sucedem-se os estudos em que se expõe a marginalidade de Camões, e os fatos relativos à sua passagem pela corte lisboeta e pela consequente estadia no Oriente que parecem mesmo se confirmar. Excluído dos círculos intelectuais que frequentavam o Paço, encarcerado na prisão do Tronco, era já um poeta marginal quando vivia em Lisboa; sua partida para a Índia, na condição de reles soldado, como já se tem observado, foi uma espécie de degredo, um expurgo mal disfarçado. Entretanto, se a exclusão do poeta tem sido abordada por diversos autores da nova vertente crítica, não foi ainda textualmente demonstrado de que modo e até que ponto sua experiência de banimento constitui fator genético e semântico na composição d'Os Lusíadas; o seu resgate do poético revela um contexto tão despercebido pela crítica quanto o texto o fora” (Nóbrega, 2012, p. 38).

3 “[...], enquanto alguns autores renascentistas ainda se mantêm presos ao fantástico, outros, e entre eles Camões, optam pelo realismo: [...]." (Rosa, 1998, p. 256). Todavia, nos perguntamos neste ponto se fantasia e realismo podem ser categorizados separadamente para tratar da questão, levando em conta principalmente a época de Camões.

4 Cabe lembrar aqui que em O soldado prático (1564), “a Índia assume também para Diogo do Couto o aspecto de um perfeito paraíso perdido, contrastando a pureza da terra com a impureza dos homens [...]" (Machado, 1983, p. 39). 